\title{
Physician burnout: Who will protect us from ourselves?
}

\author{
Michael Fralick MD, Ken Flegel MDCM MSc
}

See related analysis on page 761 and at www.cmaj.ca/lookup/doi/10.1503/cmaj.131053, and infographic, www.cmaj.ca/lookup/suppl /doi:10.1503/cmaj.140588/-/DC2

$\mathrm{W}$ hen the workday ends at Volkswagen, so does an employee's access to company email. Atos, an information technology company with more than 80000 employees, is going one step further. It is eliminating company email. The Bank of Montreal, following the lead of Goldman Sachs Group Inc., is insisting that its junior bankers take weekends off. Businesses have realized the unintended consequence of their employees always being reachable: burnout. The resultant absenteeism, decreased productivity and high employee turnover rates have forced companies to take notice.

Burnout, which was first described in 1974 by American psychologist Herbert Freudenberger, is not a recognized disorder in The Diagnostic and Statistical Manual of Mental Disorders. However, the World Health Organization International Classification of Diseases (ICD-10) defines burnout as a "state of vital exhaustion." The Maslach Burnout Inventory, ${ }^{1}$ which is considered the gold standard in research studies for estimating burnout prevalence among physicians, captures three dimensions of burnout: emotional exhaustion from overwhelming work demands, depersonalization (e.g., impersonal response toward patients or coworkers) and a perceived lack of personal accomplishment. Symptoms of burnout can be physical (e.g., insomnia, fatigue, headaches, gastrointestinal upset) and psychological (e.g., irritability, cynicism, decreased concentration).

Like many common ailments, the path to burnout is set years before symptoms manifest. Many of us entered medical school as perfectionists who were not afraid of self-sacrifice. We were aware that our success in medical school would be defined by academic performance and long hours in hospital. Then we entered residency. Estimated prevalence of burnout among residents, regardless of the year of training, is as high as 50\%. ${ }^{2}$ One might expect that long hours are the major cause of resident burnout. In a related article in CMAJ, Pattani and colleagues ${ }^{3}$ highlight that the maximum allowable shift length in Canada, with some exceptions, is 26 hours. In the United States, Europe and New Zealand, the maximum is about 16 hours. However, the evidence that reducing work hours improves quality of life is lacking, and some studies show that reducing work hours leads to a worse quality of life..$^{45}$ Improving quality of life and preventing burnout will not be achieved by residents simply working fewer hours.

The demands of residency last a few years; however, careers as physicians last a lifetime. Two-thirds of Canadian physicians feel that their workload is too demanding. ${ }^{6}$ Although feeling burned out is common, it is not normal, and it is likely to affect medical practice. We seem to have little opportunity to unplug from emails, texts, phone calls and pages. Once the clinical day is over, administrative commitments, teaching responsibilities and research projects await our attention. Is it any wonder that some businesses have decided to simply turn their email systems off at the end of the workday?

Burnout is neither benign nor temporary: it can lead to anxiety, depression, substance abuse, addiction, and in rare cases, suicide. ${ }^{7}$ The consequences of physician burnout extend beyond the physician. More than half of Canadian physicians feel their family and personal lives have suffered because of the demands of their profession. ${ }^{6}$

Physician burnout can also negatively affect patient care. In one survey, more than $50 \%$ of physicians reported that they felt that tiredness, exhaustion or sleep deprivation had a negative effect on the care they delivered. ${ }^{7}$ Physicians have a professional obligation to be in good health to practise good medicine. Making correct diagnoses and appropriate therapeutic decisions, which are fundamental to the role of every physician, requires effective functioning of the mind.

Evidence-based approaches to managing burnout are lacking; however, time away from work and behaviour-modification techniques are generally used. Encouraging results from small observational and randomized trials show that mindfulness and meditation may play a protective role in the prevention and management of burnout. ${ }^{2}$

Because we know the causes of burnout, we should focus on prevention. Common-sense recommendations may prove helpful: engage in self-care (e.g., exercise, healthy eating, meditation), take regular vacations, take breaks from email, learn how and when to say no, set limits for yourself rather than letting someone else set them for you, and learn to recognize the symptoms of burnout and to ask for help. ${ }^{2.6}$ The Canadian Medical Association's website contains a number of useful resources (www.cma .ca/living/provincialphysicianhealthprograms). Continuing medical education courses are also available for those interested in learning about meditation and mindfulness techniques.

Perhaps it's time to learn a lesson from the business world. Physicians need to develop tangible strategies that encourage work-life balance and prevent burnout. If we don't, we will suffer. So will our patients.

References, www.cmaj.ca/lookup/suppl/doi:10.1503/cmaj.140588/-/DC1

Competing interests: None declared for Michael Fralick. For Ken Flegel's competing interests, see www.cmaj.ca/site/misc/cmaj_staff.xhtml

Affiliations: Michael Fralick is an internal medicine resident at the University of Toronto. Ken Flegel is Senior Associate Editor, CMAJ.

Correspondence to: CMAJ editor, pubs@cmaj.ca

CMAJ 2014. DOI:10.1503/cmaj.140588 